\title{
Renal excretion of kallikrein and eicosanoids in patients with Type 1 (insulin-dependent) diabetes mellitus. Relationship to glomerular and tubular function
}

\author{
J. N.Harvey ${ }^{1}$, A. W.Edmundson ${ }^{2}$, A.A.Jaffa ${ }^{2}$, L. L. Martin ${ }^{4}$ and R.K.Mayfield ${ }^{3}$ \\ ${ }^{1}$ Academic Unit of Medicine, The General Infirmary, Leeds, UK, ${ }^{2}$ Endocrinology-Metabolism-Nutrition Division, Department of \\ Medicine, Medical University of South Carolina, ${ }^{3}$ Veterans Affairs Medical Center, Charleston, South Carolina, and ${ }^{4}$ Research \\ Department, Pharmaceuticals Division, Ciba-Geigy Corporation, Summit, New Jersey, USA
}

Summary. Glomerular filtration rate, renal plasma flow, renal tubular sodium reabsorption (derived from lithium clearance) and renal excretion rates of kallikrein, prostaglan$\operatorname{din} E_{2}$ and systemic and renally-derived metabolites of prostacyclin and thromboxane $\mathrm{A}_{2}$ were measured in patients with Type 1 (insulin-dependent) diabetes mellitus and in normal subjects. Diabetic patients with glomerular hyperfiltration had greater active kallikrein and prostaglandin $\mathrm{E}_{2}$ excretion than patients with normal glomerular filtration rate or than normal control subjects. Both active kallikrein and prostaglandin $\mathrm{E}_{2}$ excretion correlated directly with glomerular filtration rate. Active kallikrein excretion correlated directly with the reabsorption of sodium in the distal tubule. The excretion rates of 6-keto prostaglandin $F_{1 \alpha}, 2,3$ dinor 6-keto prostaglandin $F_{1 \alpha}$, thromboxane $B_{2}, 2,3$ dinor thromboxane $\mathrm{B}_{2}$ and 11-dehydro thromboxane $\mathrm{B}_{2}$ excretion were not dif- ferent between the groups. This study confirms in man our previous finding of increased renal kallikrein production in the hyperfiltering streptozotocin-diabetic rat model. Given that kinins generated by kallikrein are extremely potent vasodilators and stimulate the renal production of eicosanoids that also regulate glomerular function, our findings suggest that increased kallikrein activity and prostaglandin $\mathrm{E}_{2}$ production may contribute to renal vasodilatation and hyperfiltration in human diabetes. The localization of kallikrein in the distal connecting tubule makes it plausible that altered sodium transport in the distal tubule may be a signal to increase generation of kallikrein.

Key words: Type 1 (insulin-dependent) diabetes mellitus, glomerular filtration rate, kallikrein, prostaglandin $\mathrm{E}_{2}$, prostacyclin, thromboxanes, renal tubule.
An increase in glomerular filtration rate (GFR) above normal occurs in the early course of Type 1 (insulin-dependent) diabetes mellitus [1]. Both retrospective and prospective studies in man show that hyperfiltration is predictive of progression to proteinuria $[2,3]$. In diabetic rats with hyperfiltration, the accompanying raised intraglomerular pressure accelerates the development of nephropathy $[4,5]$. Glomerular haemodynamic measurements in these rats show that reduced afferent arteriolar resistance is the principal cause of glomerular capillary hyperperfusion and raised intracapillary pressure $[6,7]$.

The factors which mediate glomerular vasodilatation in diabetes remain uncertain. Increased circulating levels of glucagon and growth hormone may together contribute, but are probably not independently responsible $[8,9]$. Amongst vasoactive substances produced within the kidney, animal model studies support a role for vasodilatory eicosanoids [10]. We recently reported that renal levels and excretion of kallikrein are increased in streptozotocin-diabetic rats with hyperfiltration, and treatment with a kallikrein inhibitor reduced GFR and renal plasma flow (RPF) to normal [11]. In an earlier clinical study, we found that active kallikrein excretion is increased in poorly controlled Type 1 diabetes, and falls with improved diabetic control [12]. These changes were not studied in relation to renal haemodynamics.

Several findings suggest that kallikrein and its kinin product participate in regulating glomerular function. Kallikrein is synthesized and secreted from distal connecting tubule cells, but this portion of the nephron makes a second loop, after the macula densa, and encircles the afferent arteriole $[13,14]$. Kallikrein resides in basolateral membranes of connecting tubule cells, and adjacent principal cells produce kininogen substrate [15]. Therefore, enzyme and substrate are located such that kinins could be generated in the interstitium surrounding the preglomerular circulation. In vitro, kinins applied anti-lumenally reduce the resistance of perfused afferent arterioles [16]. Finally, kinins stimulate production of vasodilatory eicosanoids (prostaglandin (PG) $\mathrm{E}_{2}$ and prostacyclin) by afferent arterioles and glomerular mesangial cells $[17,18]$. 
In the present study of Type 1 diabetic patients, we measured GFR, RPF and the simultaneous renal excretion rates of kallikrein, prokallikrein, 6-keto- $\mathrm{PGF}_{1 \alpha}$ (the stable metabolite of prostacyclin), $\mathrm{PGE}_{2}$ and thromboxane (TX) $\mathrm{B}_{2}$ (the stable metabolite of TXA ${ }_{2}$ ). The excretion of systemically derived metabolites of $\mathrm{PGI}_{2}$ and $\mathrm{TXA}_{2}$ were also measured. Renal tubular sodium handling was assessed by measurement of lithium clearance.

\section{Subjects and methods}

\section{Protocol}

Thirty-one Type 1 diabetic patients and nine normal control subjects were studied. The protocol was approved by the ethical committee (Leeds) and the Institutional Review Board for Human Research (South Carolina). Informed consent was obtained from all subjects. Subjects were asked to avoid coffee, tea and cigarettes on the study day. Most diabetic patients had their usual insulin dose by subcutaneous injection. In the fasting state or after a light, low protein breakfast, each subject had venous cannulae inserted and then rested at least $1 \mathrm{~h}$ prior to GFR and RPF measurement. Subjects drank $300 \mathrm{ml}$ water every $30 \mathrm{~min}$, beginning immediately after cannula insertion and continuing throughout the study.

GFR and RPF were measured in 10 of the diabetic subjects (South Carolina) by the direct clearance of inulin and para-aminohippurate (PAH), respectively, given by constant infusion [19]. The average of three consecutive 30 min clearance measurements was calculated for each patient. In 21 diabetic ( 8 with hyperfiltration) and 9 control subjects (Leeds), single injection clearances of ${ }^{51} \mathrm{Cr}$ EDTA [20] and ${ }^{125}$ I-iodohippuran [21] were used to measure GFR and RPF. Because renal plasma clearance of ${ }^{51} \mathrm{Cr}$-EDTA underestimates GFR relative to inulin, EDTA clearances were corrected according to the method of Brochner-Mortensen [22]. The single injection iodohippuran clearances were corrected according to the method of Blaufox and Merrill [21]. The upper limit of normal GFR was calculated as the mean +2 SD of the GFR of the normal control subjects $\left(132 \mathrm{ml} \cdot \mathrm{min}^{-1} \cdot 1.73 \mathrm{~m}^{-2}\right)$. The diabetic patients were divided into normal or hyperfiltering subgroups.

Arterial blood pressure was measured using a Dinamap monitor (Critikon, Tampa, Fla. USA) at $30 \mathrm{~min}$ intervals throughout the study and mean diastolic and systolic pressures during the clearance measurements were calculated for each subject. Plasma glucose was measured at the beginning, midpoint and end of the clearance determinations. From urine collected during the clearance measurements the renal excretion rates of kallikrein (active and prokallikrein) and eicosanoids were measured. Samples for eicosanoid measurement were obtained only from the 30 subjects who underwent lithium clearance determination. Albumin excretion rate was assessed from the mean of at least two timed overnight urine collections obtained prior to the clearance studies.

From the total group of 40 subjects, 30 subjects ( 9 controls, 13 diabetic patients with normal GFR, and 8 hyperfiltering patients) underwent a lithium clearance determination simultaneously with GFR and RPF measurement. Lithium carbonate $(650 \mathrm{mg})$ was given orally at 22.00 hours the evening before the study. Lithium concentration was determined in serum obtained at the beginning and end of the GFR and RPF measurements and in an aliquot of urine. Proximal and distal tubular reabsorption rates were calculated as previously described [23].

\section{Assays}

Inulin and $\mathrm{PAH}$ in plasma and urine were measured as previously described $[24,25]$. Lithium was measured by atomic absorption spectrometry. Urinary kallikrein was measured by RIA using a polyclo-
Table 1. Age, duration of Type 1 (insulin-dependent) diabetes, $\mathrm{HbA}_{1 \mathrm{c}}$ and overnight albumin excretion rate in control and diabetic subjects

\begin{tabular}{lcccc}
\hline & $\begin{array}{l}\text { Age } \\
\text { (years) }\end{array}$ & $\begin{array}{l}\text { Duration } \\
\text { of diabetes } \\
\text { (years) }\end{array}$ & $\begin{array}{l}\mathrm{HbA}_{\mathrm{Ic}} \\
(\%)\end{array}$ & $\begin{array}{l}\text { Albumin ex- } \\
\text { cretion rate } \\
\left(\mu \mathrm{g} \cdot \mathrm{min}^{-1}\right)\end{array}$ \\
\hline $\begin{array}{l}\text { Normal control } \\
\text { subjects }\end{array}$ & $31 \pm 2$ & - & $6.2 \pm 0.1$ & $5 \pm 1$ \\
$\begin{array}{l}\text { Normal GFR } \\
\text { diabetic patients }\end{array}$ & $31 \pm 2$ & $11 \pm 1$ & $8.2 \pm 0.4$ & $12 \pm 4$ \\
$\begin{array}{l}\text { Hyperfiltering } \\
\text { diabetic patients }\end{array}$ & $26 \pm 2$ & $10 \pm 2$ & $9.0 \pm 1.0$ & $7 \pm 2$ \\
\hline
\end{tabular}

GFR, Glomerular filtration rate

nal antibody raised against human urinary active kallikrein [26]. A parallel sample was treated with trypsin to convert prokallikrein to active kallikrein. Assay of total urinary kallikrein in this sample allowed determination of prokallikrein concentration by subtracting the concentration of active kallikrein in the untreated sample [26]. The stable metabolites of $\mathrm{TXA}_{2}\left(\mathrm{TXB}_{2}, 2,3\right.$ dinor $\mathrm{TXB}_{2}$, and 11-dehydro- $\mathrm{TXB}_{2}$ ) and $\mathrm{PGI}_{2}$ (6-keto-PGF ${ }_{1 \alpha}$, and 2,3 dinor 6-keto-PGF $\mathrm{PG}_{1 \alpha}$ ), as well as $\mathrm{PGE}_{2}$, were measured in urine by gas chromotography, mass spectrometry [27]. Urine was stored at $-40^{\circ} \mathrm{C}$ prior to measurement of eicosanoid and kallikrein concentrations. Urinary albumin was measured by RIA and $\mathrm{HbA}_{1 c}$ by isoelectric focussing. The glucose concentration in plasma and urine was measured with a Glucose Analyzer 2 (Beckman, Fullerton, Calif., USA).

\section{Statistical analysis}

GFR, RPF and lithium clearance are expressed per $1.73 \mathrm{~m}^{2}$ body surface area. All data are expressed as the mean \pm SEM. Differences between the three groups of subjects were assessed by one-way analysis of variance (ANOVA), with subsequent $t$-tests applied where ANOVA was significant. Data were logarithmically transformed if non-linear. Correlations were calculated by linear regression analysis.

\section{Results}

The age, duration of diabetes, $\mathrm{HbA}_{1 \mathrm{c}}$ and albumin excretion rate are shown in Table 1 for diabetic patients with normal or elevated GFR and for control subjects. The age of the three groups was similar, and there was no difference in duration of diabetes, $\mathrm{HbA}_{1 \mathrm{c}}$ or albumin excretion between the two groups of diabetic patients. All subjects were normotensive and there were no differences in blood pressure between the groups. Average blood pressure in the control, normal GFR diabetic and hyperfiltering diabetic patients was $132 / 81,126 / 79$ and $123 / 78 \mathrm{~mm} \mathrm{Hg}$ respectively. Blood pressure did not show a change during the renal function measurements. During the clearance studies, mean plasma glucose in control, normal GFR diabetic and hyperfiltering diabetic subjects was $4.1 \pm 0.2$, $6.2 \pm 0.9$ and $7.4 \pm 1.3 \mathrm{mmol} \cdot \mathrm{l}^{-1}$ respectively $(p$, NS). The mean GFR in hyperfiltering patients was $151 \pm 6 \mathrm{ml} \cdot \mathrm{min}^{-1}(p<0.001)$ compared to $110 \pm 2$ in normal filtering patients and $109 \pm 4$ in control subjects (Fig.1). Although RPF tended to be higher in hyperfiltering patients it was not significantly increased, nor was the 


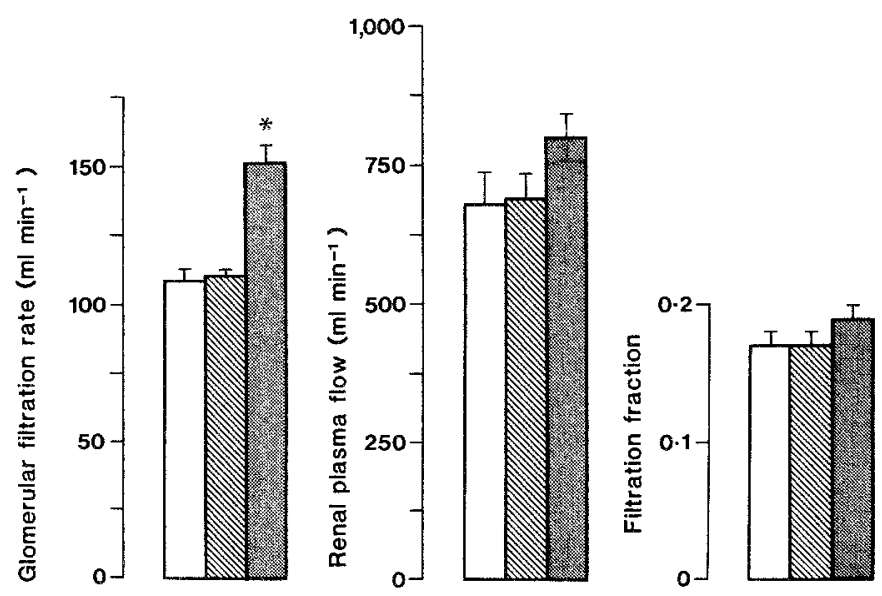

Fig.1. Glomerular filtration rate, renal plasma flow and filtration fraction in the normal subjects $(\square)$, in normal glomerular filtration rate diabetic patients $(\mathbb{W})$ and in hyperfiltering diabetic patients (閶). ${ }^{*} p<0.001$ vs each of the other two groups

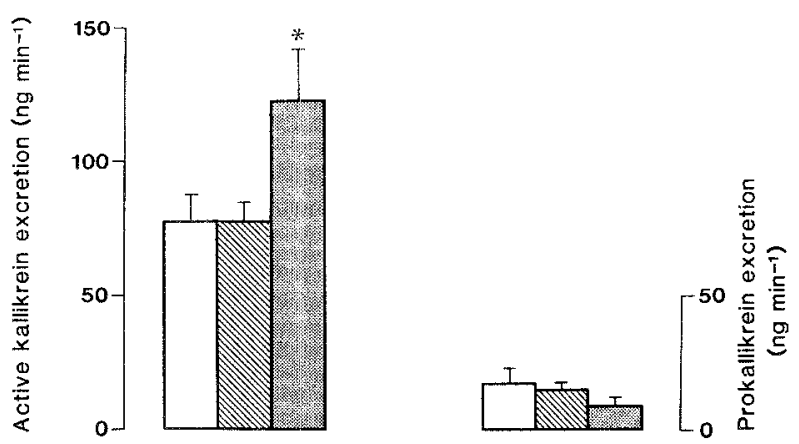

Fig. 2. Active and prokallikrein excretion rates in the normal subjects ( $\square$ ), in normal glomerular filtration rate diabetic patients ( and in hyperfiltering diabetic patients (国). ${ }^{*} p<0.05$ vs each of the other two groups

filtration fraction significantly increased in the hyperfiltering patients.

Active kallikrein and prokallikrein excretion rates are shown in Figure 2. Active kallikrein excretion was increased by more than $50 \%$ in hyperfiltering diabetic patients compared to normal filtering patients or normal subjects $(p<0.05)$. Active kallikrein excretion was nearly identical in the latter two groups. In the three groups of subjects collectively, active kallikrein excretion correlated directly with GFR $(r=0.37, p<0.02)$. There was no difference in prokallikrein excretion between the three groups (Fig.2).

Excretion of $\mathrm{TXB}_{2}$ and 6-keto-PGF $\mathrm{PF}_{1 \alpha}$, the metabolites of $\mathrm{TXA}_{2}$ and $\mathrm{PGI}_{2}$ produced intrarenally, showed no significant differences between the groups, expressed either as an absolute excretion rate or as quantity per milligram of urinary creatinine (Table 2). In addition, the excretion of dinor metabolites of systemically derived $\mathrm{TXA}_{2}$ and $\mathrm{PGI}_{2}$, as well as 11-dehydro $\mathrm{TXB}_{2}$, were unchanged in diabetic patients. However, $\mathrm{PGE}_{2}$ excretion wasincreased in hyperfiltering diabetic patients compared with either normal filtering diabetic or control subjects. $\mathrm{PGE}_{2}$ excretion $\left(\mathrm{pg} \cdot \mathrm{min}^{-1}\right)$ correlated with GFR $(r=0.36, p=0.05)$ but did not correlate with the excretion rate of active kallikrein.
Lithium clearance together with calculated fractional and absolute sodium reabsorption rates are given in Table 3. Sodium and water excretion rates were not different between any of the groups. However, the absolute reabsorption of sodium in the proximal tubule was significantly greater in the hyperfiltering patients compared with normal GFR diabetic patients or normal control subjects ( $p<0.001$ vs both). Taking normal and diabetic subjects together, active kallikrein excretion correlated directly with both fractional ( $r=0.46, p<0.02$, Fig. 3) and absolute $(r=0.38, p<0.05)$ distal tubular sodium reabsorption and inversely with sodium excretion $(r=-0.36$, $p=0.05$ ). Eicosanoid excretion rate did not correlate with distal sodium reabsorption.

\section{Discussion}

These data show that renal excretion of active kallikrein is increased in Type 1 diabetic patients with glomerular hyperfiltration, compared to diabetic patients with normal GFR or normal subjects. These findings are consistent with our previous observations in the streptozotocindiabetic rat, in which inhibition of kallikrein with aprotinin reduced GFR to normal [11]. The latter suggests that increased kallikrein excretion in diabetic humans or rats with hyperfiltration is not secondary to raised GFR.

The factors responsible for increased kallikrein in diabetes-induced hyperfiltration are not certain. From the present data, it is unlikely that washout accounts for the increased excretion because urine flow rates were similar in the three groups, and active kallikrein was increased whereas prokallikrein showed no difference. Renal kallikrein excretion increases in response to dietary sodium restriction and there is evidence to suggest that sodium-retaining steroids stimulate renal kallikrein production and excretion [28]. In a previous study of Type 1 diabetic patients on constant sodium intake, increased excretion of active kallikrein was related to poor glycaemic control [12]. In the present study $\mathrm{HbA}_{1 \mathrm{c}}$ was not significantly different between the three groups. However, few patients with poor control were studied; also, since in this study sodium intake was not strictly controlled, inter-subject variation in sodium intake could have increased the variation in active kallikrein excretion and obscured the relationship with glycaemic control. Mayfield et al. [12] have clearly shown the effect of intensive insulin treatment on active kallikrein excretion but further studies are needed to investigate the relationship of changes in active kallikrein to changes in GFR. Although sodium intake was not controlled in the current study, urinary excretion did not differ significantly between the groups, suggesting that sodium intake was neither different nor responsible for the increased active kallikrein excretion in the hyperfiltering patients. Acute water diuresis does not alter kallikrein excretion [28].

To further examine the relationship between kallikrein excretion and tubular handling of sodium in diabetes, we measured proximal and distal tubular reabsorption rates by lithium clearance [23]. The validity of the lithium clearance technique depends on two assumptions: firstly, that 
Table 2. Urinary excretion of renal and systemically derived eicosanoids, expressed relative to creatinine excretion and as absolute excretion rate

\begin{tabular}{|c|c|c|c|c|c|c|}
\hline & \multicolumn{6}{|c|}{$\mathrm{pg} \cdot \mathrm{mg}$ urinary creatinine $\mathrm{e}^{-1}$} \\
\hline & $\mathrm{TXB}_{2}$ & $\begin{array}{l}\text { Dinor } \\
\mathrm{TXB}_{2}\end{array}$ & $\begin{array}{l}\text { 11-Dehydro } \\
\mathrm{TXB}_{2}\end{array}$ & $\begin{array}{l}\text { 6-Keto } \\
\text { PGF }_{1 \alpha}\end{array}$ & $\begin{array}{l}\text { Dinor 6-Keto } \\
\text { PGF }_{1 \alpha}\end{array}$ & $\mathrm{PGE}_{2}$ \\
\hline Normal control subjects & $45 \pm 6$ & $252 \pm 46$ & $993 \pm 267$ & $225 \pm 36$ & $802 \pm 115$ & $118 \pm 47^{b}$ \\
\hline Normal GFR diabetic patients & $37 \pm 4$ & $232 \pm 38$ & $885 \pm 122$ & $236 \pm 46$ & $892 \pm 143$ & $168 \pm 40^{\mathrm{a}}$ \\
\hline Hyperfiltering diabetic patients & $\begin{array}{l}58 \pm 11 \\
\mathrm{pg} \cdot \min ^{-1}\end{array}$ & $269 \pm 55$ & $931 \pm 103$ & $200 \pm 36$ & $796 \pm 132$ & $435 \pm 139$ \\
\hline Normal GFR diabetic patients & $42 \pm 3$ & $289 \pm 62$ & $1025 \pm 117$ & $277 \pm 49$ & $1053 \pm 154$ & $196 \pm 44$ \\
\hline Hyperfiltering diabetic patients & $61 \pm 12$ & $280 \pm 61$ & $957 \pm 94$ & $212 \pm 43$ & $841 \pm 158$ & $427 \pm 125$ \\
\hline
\end{tabular}

${ }^{\mathrm{a}} p<0.05,{ }^{\mathrm{b}} p<0.02$ vs hyperfiltering diabetic patients.

TX, Thromboxane; PG, prostaglandin; GFR, glomerular filtration rate

Table 3. Glomerular and tubular function in normal control subjects, in normal GFR Type 1 diabetic patients and hyperfiltering diabetic patients

\begin{tabular}{|c|c|c|c|c|c|c|c|c|c|}
\hline & \multirow{2}{*}{$\begin{array}{l}\text { GFR } \\
\left(\mathrm{ml} \cdot \mathrm{min}^{-}\right.\end{array}$} & \multirow{2}{*}{$\begin{array}{l}\mathrm{C}_{\mathrm{Li}} \\
\left(\mathrm{ml} \cdot \mathrm{min}^{-1}\right.\end{array}$} & \multicolumn{2}{|c|}{$\begin{array}{l}\text { Proximal reabsorption } \\
\text { of sodium }\end{array}$} & \multicolumn{2}{|c|}{$\begin{array}{l}\text { Distal reabsorption } \\
\text { of sodium }\end{array}$} & \multirow{2}{*}{$\begin{array}{l}\text { Urine flow } \\
\left(\mathrm{ml} \cdot \mathrm{min}^{-1}\right)\end{array}$} & \multirow{2}{*}{$\begin{array}{l}\text { Urinary } \mathrm{Na} \\
\text { excretion } \\
\left(\mu \mathrm{mol} \cdot \mathrm{min}^{-1}\right)\end{array}$} & \multirow{2}{*}{$\begin{array}{l}\text { Urine } \\
\text { glucose } \\
\left(\mathrm{mmol} \cdot \mathrm{1}^{-1}\right)\end{array}$} \\
\hline & & & $\begin{array}{l}\text { Fractional } \\
(\%)\end{array}$ & $\begin{array}{l}\text { Absolute } \\
\left(\mathrm{mmol} \cdot \mathrm{min}^{-1}\right)\end{array}$ & $\begin{array}{l}\text { Fractional } \\
(\%)\end{array}$ & $\begin{array}{l}\text { Absolute } \\
\left(\mathrm{mmol} \cdot \mathrm{min}^{-1}\right)\end{array}$ & & & \\
\hline $\begin{array}{l}\text { Normal } \\
\text { control subjects }\end{array}$ & $109 \pm 4$ & $23 \pm 2$ & $79 \pm 2$ & $11.9 \pm 0.4$ & $94 \pm 1$ & $3.0 \pm 0.3$ & $6.7 \pm 0.3$ & $222 \pm 32$ & $0.3 \pm 0.01^{b}$ \\
\hline $\begin{array}{l}\text { Normal GFR } \\
\text { diabetic patients }\end{array}$ & $109 \pm 3$ & $24 \pm 1$ & $78 \pm 1$ & $11.8 \pm 0.4$ & $95 \pm 1$ & $3.2 \pm 0.2$ & $6.4 \pm 0.7$ & $185 \pm 28$ & $2.0 \pm 1.0$ \\
\hline $\begin{array}{l}\text { Hyperfiltering } \\
\text { diabetic patients }\end{array}$ & $144 \pm 5^{\mathrm{a}}$ & $26 \pm 1$ & $82 \pm 1$ & $16.3 \pm 0.5^{a}$ & $96 \pm 1$ & $3.5 \pm 0.2$ & $6.1 \pm 0.4$ & $141 \pm 25$ & $3.9 \pm 2.4$ \\
\hline
\end{tabular}

${ }^{\mathrm{a}} p<0.001,{ }^{\mathrm{b}} p<0.02$ vs each of the other two groups. GFR, Glomerular filtration rate; $\mathrm{C}_{\mathrm{Li}}$, lithium clearance; Na, sodium

lithium, sodium and water are reabsorbed in similar proportions in proximal convoluted and straight tubules. Micropuncture measurements support this assumption [29-31]. Secondly, that lithium is not reabsorbed in the distal nephron (loop of Henle, distal tubule and collecting duct). This has been tested in man using diuretics which act on the distal tubule [32], and at moderate or high sodium intake, lithium is not reabsorbed in this section of the nephron. The subjects in our study were on unrestricted sodium intake and urinary sodium excretion suggested a moderate sodium intake. Finally, glucose excretion by the diabetic subjects in our study was minimal and therefore unlikely to have influenced lithium clearance.

Lithium clearance measurements indicated that the increased filtration of water and sodium in hyperfiltering patients is compensated largely by increased reabsorption in the proximal tubule. There was no correlation between kallikrein excretion and proximal tubular sodium reabsorption rate. However, kallikrein excretion rate correlated directly with reabsorption of sodium in the distal tubule and inversely with renal sodium excretion. Although a correlation between distal sodium reabsorption and kallikrein excretion rate does not prove a causal relationship, other observations are in support of such a relationship. Mineralocorticoid-stimulated distal sodium reabsorption is associated with increased kallikrein [28]. In addition, thiazide diuretics, which inhibit sodium reabsorption in the connecting tubule [33], the site of kallikrein produc- tion $[13,14]$, reduce kallikrein excretion [34]. It is also interesting that distal nephron sodium reabsorption is stimulated by insulin $[35,36]$ and prolonged hyperinsulinaemia may increase renal kallikrein synthesis [37]. Therefore, it is possible that the higher systemic levels of insulin in patients treated with insulin contribute to increased renal kallikrein production.

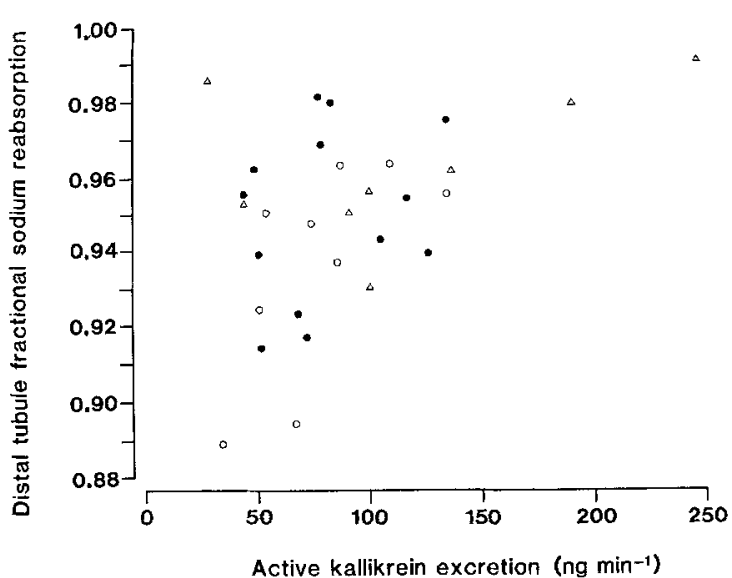

Fig. 3. The relationship between active kallikrein excretion rate and fractional sodium reabsorption in the distal tubule in normal subjects $(O)$, in normal glomerular filtration rate diabetic patients $(\bullet)$ and in hyperfiltering diabetic patients $(\triangle)$. For all subjects: $r=0.46$, $p<0.02$ 
Finally, we found increased renal excretion of $\mathrm{PGE}_{2}$ in hyperfiltering patients, whereas patients with normal GFR had excretion similar to control subjects. Excretion of renal and systemic (dinor and 11-dehydro) metabolites of $\mathrm{PGI}_{2}$ and $\mathrm{TXA}_{2}$ were not altered in either group of diabetic patients. Four previous studies have measured urinary eicosanoids in Type 1 diabetic patients with hyperfiltration. Two studies found increased 6-keto$\mathrm{PGF}_{1 \alpha}$ excretion and no change in $\mathrm{TXB}_{2}$ excretion $[38,39]$. One of these also found no change in urinary $\mathrm{PGE}_{2}[39]$. A third study found no change in $\mathrm{PGE}_{2}$ or 6-keto- $\mathrm{PF}_{1 \alpha}$ excretion [40]. In contrast to our study, in which eicosanoids were measured in urine from timed collections during clearance measurements with water loading, the previous studies measured overnight or 24-h excretion. However, Hommel et al. [41] using a study design similar to ours found increased urinary $\mathrm{PGE}_{2}$ patients with increased GFR. GFR and $\mathrm{PGE}_{2}$ excretion were both reduced by indomethacin. In all of these previous studies urinary eicosanoids were measured by direct RIA. We employed gas chromatography-mass spectrometry, which separately quantitates the excretion of metabolites of systemically produced $\mathrm{PGI}_{2}$ and $\mathrm{TXA}_{2}$ from the renal metabolites of these eicosanoids [27]. This eliminates the possible crossreactivity of the systemic metabolites, which are excreted in much higher concentrations in urine than $\mathrm{TXB}_{2}$ and 6-keto-PGF ${ }_{1 \alpha}$.

The possibility that increased renal kallikrein and $\mathrm{PGE}_{2}$ production could be related is suggested by studies of isolated glomerular arterioles and cultured mesangial cells. In these tissues, kinins stimulate $\mathrm{PGE}_{2}$ production $[17,18]$. Moreover, $\mathrm{PGE}_{2}$ production is increased in glomeruli isolated from streptozotocin-diabetic rats with hyperfiltration [42], a model which also shows increased kallikrein excretion [11].

In summary, our study shows that Type 1 diabetic patients with glomerular hyperfiltration demonstrate the same renal kallikrein abnormality previously found in a rat model of diabetic hyperfiltration. The increase in renal kallikrein excretion may be related to the changes in distal tubular sodium transport and renal eicosanoid abnormalities seen in diabetes.

Acknowledgements. JNH was supported by the locally-organised Research Scheme of the Yorkshire Regional Health Authority. AAJ is the recipient of a Career Development Award from the American Diabetes Association. This research was also supported by the Research Service of the United States Department of Veterans Affairs (RKM) and a grant from the National Institutes of Health, RR001070. We are grateful for technical assistance from M.Bigelow, B. Hamilton, P. Martin, K. Sutton and the staff of the General Clinical Research Center at The Medical University of South Carolina.

\section{References}

1. Mogensen CE, Andersen MJF (1973) Increased kidney size and glomerular filtration rate in early juvenile diabetes. Diabetes 22 : 706-712

2. Mogensen CE, Christensen CK (1984) Predicting diabetic nephropathy in insulin-dependent patients. $N$ Engl $J$ Med 311: 89-93
3. Rudberg S, Persson B, Dahlquist G (1992) Increased glomerular filtration rate as a predictor of diabetic nephropathy - An 8-year prospective study. Kidney Int 41: 822-828

4. Zatz RM, Meyer TW, Rennke HG, Brenner BM (1985) Predominance of hemodynamic rather than metabolic factors in the pathogenesis of diabetic glomerulopathy. Proc Natl Acad Sci 82: 5963-5967

5. Zatz RM, Dunn BR, Meyer TW, Anderson S, Rennke HG, Brenner BM (1986) Prevention of diabetic glomerulopathy by pharmacological amelioration of glomerular capillary hypertension. J Clin Invest 77: 1925-1930

6. Hostetter'TH, Troy JL, Brenner BM(1981) Glomerular hemodynamics in experimental diabetes mellitus. Kidney Int 19:410-415

7. Jensen PK, Christiansen JS, Steven K, Parving HH (1987) Strict metabolic control and renal function in the streptozotocin diabetic rat. Kidney Int 31: 47-51

8. Wiseman MJ, Redmond S, House F, Keen H, Viberti GC (1985) The glomerular hyperfiltration of diabetes is not associated with elevated plasma levels of glucagon and growth hormone. Diabetologia 28: 718-721

9. Christiansen JS (1985) Glomerular hyperfiltration in diabetes mellitus. Diabetic Med 2:235-239

10. Jensen PK, Steven K, Blaehr H, Christiansen JS, Parving HH (1986) Effects of indomethacin on glomerular hemodynamics in experimental diabetes. Kidney Int 29: 490-495

11. Harvey JN, Jaffa AA, Margolius HS, Mayfield RK (1990) Renal kallikrein and hemodynamic abnormalities of diabetic kidney. Diabetes 39: 299-304

12. Mayfield RK, Margolius HS, Levine JH, Wohltmann HJ, Loadholt CB, Colwell JA (1984) Urinary kallikrein excretion in insulin-dependent diabetes mellitus and its relationship to glycemic control. J Clin Endocrinol Metab 59: 278-286

13. Barajas L, Powers K, Carretero OA, Scicli AG, Inagami T (1986) Immunocytochemical localization of renin and kallikrein in the rat renal cortex. Kidney Int 29: 965-970

14. Vio CP, Figueroa CD, Caorsi I (1988) Anatomical relationship between kallikrein containing tubules and the juxtaglomerular apparatus in the human kidney. Am J Hypertens 1: 269-271

15. Figueroa CD, MacIver AG, Mackenzie JC, Bhoola KD (1988) Localization of immunoreactive kininogen and tissue kallikrein in the human nephron. Histochemistry 89: 437-442

16. Edwards RM (1985) Response of isolated renal arterioles to acetylcholine, dopamine, and bradykinin. Am J Physiol 248: F183F189

17. Hura CE, Kunau RT (1988) Angiotensin II-stimulated prostaglandin production by canine renal afferent arterioles. Am J Physiol 254: F734-F738

18. Uglesity A, Kreisberg JI, Levine L (1983) Stimulation of arachidonic acid metabolism in rat kidney mesangial cells by bradykinin, antidiuretic hormone, and their analogues. Prostaglandins Leukotrienes Med 10: 83-93

19. Smith HW (1951) The kidney. Structure and function in health and disease. Oxford University Press, Oxford

20. Harries JD, Mildenberger RR, Malowany AS, Drummond KN (1972) A computerized cumulative integral method for the precise measurement of the glomerular filtration rate. Proc Soc Exp Biol Med 140: 1148-1155

21. Blaufox MD, Merrill JP (1966) Simplified hippuran clearance. Measurement of renal function in man with simplified hippuran clearances. Nephron 3: 274-281

22. Brochner-Mortensen J (1978) Routine methods and their reliability for assessment of glomerular filtration rate in adults. Danish Med Bull 25: 181-202

23. Thomsen K (1984) Lithium clearance: a new method for determining proximal and distal tubular reabsorption of sodium and water. Nephron 37: 217-223

24. Roe JH, Epstein JH, Goldstein NP (1949) A photometric method for the determination of inulin in plasma and urine. $J$ Biol Chem 178: 839-845

25. Bratton C, Marshall EK (1939) A new coupling method for sulfanilamide determination. J Biol Chem 128: 537-550 
26. Shimamoto K, Chao J, Margolius HS (1982) A method for determining human urinary inactive kallikrein (prekallikrein). Tohoku J Exp Med 137:269-274

27. Martin LL, Schaffer AV, Piraino A et al. (1991) Pharmacokinetics of CGS 12970 and inhibition of thromboxane synthesis after oral administration in healthy adults. Clin Pharmacol Ther 49: 433-441

28. Margolius HS, Horwitz D, Geller RG et al. (1974) Urinary kallikrein excretion in normal man. Circ Res 35:812-819

29. Hayslett JP, Kashgarian M (1979) A micropuncture study of the renal handling of lithium. Pflugers Arch 380: 159-163

30. Thomsen K, Holstein-Rathlou N-H, Leyssac PP (1981) Comparison of three measures of proximal tubular reabsorption: lithium clearance, occlusion time and micropuncture. Am J Physiol 241: F348-F355

31. Shirley DG, Walter SJ, Thomsen K (1983) A comparison of micropuncture and lithium clearance methods in the assessment of renal tubular function in rats with diabetes insipidus. Pflugers Arch 399: 226-270

32. Atherton JC, Green R, Hughes S et al. (1987) Lithium clearance in man: effects of dietary salt intake, acute changes in extracellular fluid volume, amiloride and frusemide. Clin Sci 73: 645-651

33. Shimuzu T, Yoshitomi K, Nakamura M, Imai M (1988) Site and mechanism of action of trichlormethiazide in rabbit distal nephron segments perfused in vitro. J Clin Invest 82: 721-730

34. Marin-Grez M, Odigie P (1990) Physiological role of renal kallikrein. Kidney Int 37: 1165 (Abstract)

35. DeFronzo RA, Cooke CR, Andres R, Faloona GR, Davis PJ (1975) The effect of insulin on renal handling of sodium, potassium, calcium, and phosphate in man. J Clin Invest 55: 845-855

36. Norgaard K, Jensen T, Skott P et al. (1991) Effects of insulin on renal hemodynamics and sodium handling in normal subjects. Scand J Clin Lab Invest 51:367-376
37. Jaffa AA, Miller DH, Bailey GS, Chao J, Margolius HS, Mayfield RK (1987) Abnormal regulation of renal kallikrein in experimental diabetes. Effects of insulin on prokallikrein synthesis and activation. I Clin Invest 80: 1651-1659

38. Gambardella S, Andreani D, Cancelli A et al. (1988) Renal hemodynamics and urinary excretion of 6-keto-prostaglandin $F_{1 \alpha}$ and thromboxane $B_{2}$ in newly diagnosed type 1 diabetic patients. Diabetes 37: 1044-1048

39. Viberti GC, Benigni A, Bognetti E, Remuzzi G, Wiseman MJ (1989) Glomerular hyperfiltration and urinary prostaglandins in type 1 diabetes mellitus. Diabetic Med 6: 219-223

40. Esmatjes E, Fernandez MR, Halperin I et al. (1985) Renal hemodynamic abnormalities in patients with short term insulin-dependent diabetes mellitus: role of renal prostaglandins. J Clin Endocrinol Metab 60: 1231-1236

41. Hommel E, Mathiesen E, Arnold-Larsen S, Edsberg B, Olsen UB, Parving HH (1987) Effects of indomethacin on kidney function in type 1 (insulin-dependent) diabetic patients with nephropathy. Diabetologia 30: 78-81

42. Craven PA, DeRubertis FR (1989) Role for local prostaglandin and thromboxane production in the regulation of glomerular filtration rate in the rat with streptozocin-induced diabetes. J Lab Clin Med 113: 674-681

Received: 15 January 1992

and in revised form: 7 May 1992

Dr. J.N.Harvey

St. James University Hospital

Beckett Street

Leeds LS97TF

UK 